\title{
A EXPANSÃo do AGRONEGÓCIO COOPERATIVO NA REGIÃO SUL DO BRASIL NOS ANOS 2000
}

Wilian Padilha ${ }^{1}$

Fernando dos Santos Sampaio ${ }^{2}$

\begin{abstract}
Resumo: Após os anos 2000, as cooperativas agropecuárias da Região Sul do país apresentaram um novo ciclo de expansão, com aumento no número de associados, empregados, produção, territórios e receitas. O crescimento geoeconômico do cooperativismo ocorreu em todos os estados do Sul, todavia, com maior intensidade nas instituições paranaenses e catarinenses, que, dessa maneira, tornaram-se o centro mais dinâmica do cooperativismo regional e nacional. O objetivo do artigo é verificar a expansão geoeconômica das cooperativas agropecuárias no Sul do Brasil a partir de 2000, analisando as particularidades de sua recente evolução em cada um dos estados sulistas. Metodologicamente, o trabalho apoiou-se no levantamento bibliográfico e tratamento e análise de dados estatísticos.
\end{abstract}

Palavras-chave: Cooperativas agropecuárias. Agronegócio. Região Sul do Brasil.

\section{THE EXPANSION OF THE COOPERATIVE AGRIBUSINESS IN THE SOUTHERN REGION OF BRAZIL IN THE YEARS 2000}

Abstract: After the 2000s, the agricultural cooperatives of the South Region of Brazil presented a new cycle of expansion, with an increase in the number of associates, employees, production, territories and revenues. The geoeconomic growth of cooperativism occurred in all the southern states, however, with greater intensity in the institutions of Paraná and Santa Catarina, which became the most dynamic center of regional and national cooperativism. The objective of this article is to verify the geoeconomic expansion of agricultural cooperatives in Southern Brazil after 2000 , analyzing the particularities of their recent evolution in each of the southern states. The methodology was based on the bibliographical survey and the treatment and analysis of statistical data.

Keywords: Agricultural cooperatives. Agribusiness. South region of Brazil.

\section{LA EXPANSIÓN DEL AGRONEGOCIO COOPERATIVO EN LA REGIÓN SUR DEL BRASIL EN LOS AÑOS 2000}

Resumen: En los años 2000, las cooperativas agropecuarias de la Región Sur de Brasil presentaron un nuevo ciclo de expansión, con aumento en el número de

\footnotetext{
1 Instituto Federal do Paraná, Colegiado Multidisciplinar, Palmas, Brasil, wilian_padilha@hotmail.com, https://orcid.org/0000-0001-7921-2409

2 Universidade Estadual do Oeste do Paraná, Departamento de Geografia, Francisco Beltrão, Brasil, fssampa@gmail.com, https://orcid.org/0000-0003-4683-0221
} 
asociados, empleados, producción, territorios y facturación. El crecimiento geoeconómico del cooperativismo ocurrió en todos los estados del Sur, pero con mayor intensidad en las instituciones paranaenses y catarinenses, que se convirtieron en el centro más dinámico del cooperativismo regional y nacional. El objetivo del artículo es verificar la expansión geoeconómica de las cooperativas agropecuarias en el Sur de Brasil a partir de 2000, analizando las particularidades de su reciente evolución en cada uno de los estados sureños. Metodológicamente, el trabajo se apoyó en el levantamiento bibliográfico y tratamiento y análisis de datos estadísticos.

Palabras clave: Cooperativas agropecuárias. Agronegocio. Región sur de Brasil.

\section{Introdução}

Desde a gênese do associativismo no Brasil, no final do século XIX, a Região Sul destaca-se no desenvolvimento do cooperativismo no meio rural. A formação sócio-espacial regional, baseada na pequena produção mercantil e caracterizada pela ocupação de imigrantes europeus, com pequenas propriedades, produção diversificada e integração ao mercado, foram fatores que impulsionaram 0 surgimento das primeiras cooperativas no Sul.

Durante a modernização da agricultura brasileira (1965-1980), devido suas capacidades de difusão das bases produtivas da agricultura capitalista, as cooperativas foram amparadas pelo Governo Federal, o que possibilitou grande expansão territorial e produtiva do setor, sobretudo na Região Sul do país. Nas décadas de oitenta e noventa do século $X X$, as mudanças no cenário político e econômico, somado aos problemas internos, como má administração, por exemplo, encaminharam as cooperativas agropecuárias à recessão, resultando em redução da capacidade produtiva e alteração socioespacial.

A partir de 2000, após o período de crise e reestruturação, o cooperativismo agropecuário retomou a fase de ascensão, com amplificação no número de cooperativas, sócios e empregados, aumento da capacidade produtiva e armazenagem e elevação das vendas e receitas. No aspecto territorial, as cooperativas expandiram-se, tanto pelo surgimento de novas instituições, como pela expansão das grandes representantes do ramo.

A Região Sul concentrou, neste contexto, as maiores cooperativas agropecuárias do país, que também estiveram entre as maiores empresas do agronegócio nacional. As cooperativas da região atuaram em várias cadeias produtivas, principalmente grãos, lácteos e proteína animal e, além da grande 
capacidade produtiva, distinguiram-se pela integração com o capital comercial e financeiro.

O objetivo do presente artigo é verificar a expansão geoeconômica das cooperativas agropecuárias na Região Sul do Brasil a partir dos anos 2000, analisando os principais indicadores estatísticos do setor no período e apurando as particularidades de seu recente desenvolvimento em cada um dos estados sulistas.

A primeira parte do texto faz uma abordagem histórica do cooperativismo agropecuário com a finalidade de ressaltar as mudanças regionais identificadas no ramo nos últimos anos, em especial, no aspecto espacial, em que as cooperativas paranaenses e catarinenses tornaram-se o centro dinâmico do cooperativismo regional, posição que outrora foi ocupado pelas associações gaúchas. Posto isso, o item seguinte retrata o contexto do agronegócio cooperativo meridional a partir de 2000, assentando-se nos dados estatísticos sobre o número de cooperativas, sócios, empregados, produção, exportações e faturamento do setor em cada um dos estados.

A metodologia empregada fundou-se na abordagem exploratória-analítica, com destaque para o levantamento bibliográfico e a coleta, tratamento e análise de dados estatísticos. Na pesquisa bibliográfica, foram ponderados trabalhos importantes sobre a evolução histórica e geoeconômica do cooperativismo regional e, alusivo aos dados estatísticos, foram considerados os dados oficiais disponibilizados pelas organizações representativas do setor na Região Sul do país, OCEPAR, OCESC, OCERGS e FECOAGRO/RS e MDIC.

\section{Aspectos históricos do cooperativismo agropecuário na Região Sul do Brasil}

A história do cooperativismo meridional remonta do final do século XIX e princípios do século XX, quando, ainda no processo de ocupação e migração, foram organizadas as primeiras cooperativas de produtores rurais no Sul. O objetivo das associações era proporcionar aos sócios acesso aos insumos e organizar o comércio da produção, atuando também, na obtenção de bens domésticos e outras funções para auxiliar a reprodução econômica e social dos associados.

As primeiras cooperativas surgiram com a participação dos imigrantes alemães, italianos, ucranianos, holandeses, japoneses e outros grupos étnicos que se instalavam no Brasil e traziam consigo experiências cooperativistas dos países de 
origem. No Rio Grande do Sul, por exemplo, o marco inicial do cooperativismo foi 1902, com a fundação da Sociedade Cooperativa Caixa de Economia e Empréstimos em Nova Petrópolis, por imigrantes alemães, tendo como objetivo a ajuda financeira mútua. ${ }^{3} \mathrm{~A}$ partir daí, desenvolveram-se nas colônias de imigrantes alemães e italianos um cooperativismo ligado aos pequenos produtores agrícolas, com o caráter de defesa da remuneração do trabalho familiar frente ao comércio e às indústrias de transformações. Essas cooperativas se restringiam à comercialização dos excedentes agrícolas e sua dependência em relação ao Estado era mínima (CORADINI, 1981).

Em Santa Catarina, a primeira cooperativa data de 1909, no município de Urussanga, no sul do estado, fundada por imigrantes italianos e chamada de Cooperprima (Cooperativa Prima do Rio Maior). A cooperativa atuava no ramo agropecuário, sobretudo no comércio de banha suína e cereais produzidos pelos cooperados. No Paraná, as cooperativas no meio rural surgiram mais tarde, a partir dos anos 1920, relacionadas às colônias de imigrantes ucranianos, poloneses, alemães, italianos, japoneses e franceses. Assim como nos movimentos gaúcho e catarinense, a falta de infraestrutura e de produtos de consumo, insumos, armazéns e a exploração mercantil foram centrais para o surgimento do ramo no estado (MORASCO, 2007; IPARDES, 1974).

Em conformidade com UNIRCOOP (2003) e Fleury (1983), este primeiro momento das cooperativas no Sul se traduziu em estratégicas individuais e coletivas para acelerar a circulação de capitais, bens, serviços e informações, atuando como substituto do Estado. As cooperativas converteram-se em alternativa para a comercialização dos produtos agropecuários e aquisição de insumos, libertando, em parte, os produtores das cadeias de intermediários e atravessadores.

No período de modernização da agricultura brasileira, as cooperativas rurais ingressaram na produção agroindustrial e, com isso, deixaram de ser uma simples resposta à intermediação do capital comercial tradicional e passaram a ser concorrentes do capital produtivo, organizando sua produção com vistas à industrialização. No contexto da modernização, as cooperativas de produtores foram incentivadas pelo Estado, tornando-se instrumentos para a difusão das novas

\footnotetext{
3 As informações sobre a primeira cooperativa no Sul não são unânimes. De acordo com o DENACOOP (2006), a primeira cooperativa agropecuária registrada foi a Società Cooperativa delle Convenzioni Agricoli, fundada em 1892, na região de Veranópolis, Rio Grande do Sul, por imigrantes italianos.
} 
técnicas, tecnologias, produtos e mercados no meio rural (GONÇALVES e VEGRO, 2004).

Os principais mecanismos de incentivo do cooperativismo foram as políticas de crédito e comercialização do Governo Federal - Sistema Nacional de Crédito Rural (SNCR) e a Política de Garantia de Preços Mínimos (PGPM), que disponibilizaram volumosas quantias de recursos subsidiados ao setor.

Com uma nova orientação econômica e produtiva e o apoio estatal, o cooperativismo rural cresceu significativamente entre as décadas de 1950 e 1980 . O modelo da cooperativa moderna, integrada ao capital comercial e industrial, com negócios com bancos, mercados estrangeiros e nacionais, se sobressaiu nas Regiões Sul e Sudeste do país. Em 1970, 71,5\% das cooperativas agropecuárias e $80 \%$ dos produtores associados estavam nessas regiões, com pequena redução em 1980, para $66 \%$ das cooperativas e $74,6 \%$ dos sócios. Das vinte e seis maiores cooperativas agropecuárias do Brasil em 1980, sete eram do Rio Grande do Sul, sete eram do Paraná e cinco de São Paulo (GONÇALVES, 1987).

Na Região Sul, o cooperativismo sul-rio-grandense obteve maior proeminência. Benetti (1992) explica que as cooperativas foram o instrumento privilegiado na realização dos objetivos do estado de disseminar as novas tecnologias e crédito, organizando e concentrando o comércio de cereais, notadamente trigo. $O$ interesse público nas cooperativas do Rio Grande do Sul tinha relação com política de substituição das importações de trigo e de estímulo ao desenvolvimento da triticultura nacional, sendo a porção setentrional do Rio Grande do Sul o local em que as cooperativas agropecuárias experimentaram o maior progresso.

Logo, as cooperativas gaúchas expandiram-se para outros ramos, principalmente a soja, envolvendo-se na industrialização, exportações e em projetos de colonização em outras regiões. As cooperativas estaduais cresceram e diversificaram atividades, assumindo o caráter de grande empresa capitalista, as "multicooperativas", registrado grande crescimento na década de setenta (DELGADO, 1985; BENETTI, 1992).

No Paraná e Santa Catarina também ocorreram expansões das cooperativas agropecuárias, principalmente após a década de 1960. O aparecimento da soja como um promissor produto de exportação brasileiro impulsionou o desenvolvimento do cooperativismo na região. Ambos os estados registraram apoio das instituições públicas estaduais na promoção do cooperativismo, como agências de assistência técnica, bancos públicos e órgãos de fomento. É importante frisar que as 
cooperativas que apresentaram ampliação geoeconômica no período de modernização agrícola estavam relacionadas as áreas de colonização de imigrantes ou descendentes, como no norte do Paraná com os imigrantes japoneses, no oeste catarinense com a ocupação mista dos italianos e alemães e noroeste gaúcho com os imigrantes italianos e alemães. Essas áreas eram, igualmente, onde o processo de modernização agrícola avançava com maior rapidez.

Ainda que o cooperativismo sulista tenha se expandido como um todo no período, houve particularidades nas trajetórias das cooperativas de cada estado. Em Santa Catarina, a título de exemplo, desenvolveu-se no período de modernização um cooperativismo ligado a pecuária de suínos, no Rio Grande do Sul houve maior destaque da produção de cereais e grãos e o Paraná apresentava uma maior diversidade, com grãos, café, pecuária de corte e leiteira.

Portanto, apesar da origem antiga, o período com maior progresso do cooperativismo agropecuário na Região Sul ocorreu entre as décadas de 1950 e 1970, quando a União e estados apoiaram com maior ênfase o avanço do setor na região. Os incentivos às cooperativas sulistas consistiram em garantia de preços e mercado aos produtos, benefícios fiscais, assistência rural, crédito subsidiado, doação de infraestruturas de armazenagem, apoio para exportação e outros. Concernente as políticas de apoio, o crédito rural foi o principal artifício e, dos $\mathrm{R} \$$ 267 bilhões aplicados no cooperativismo agropecuário entre 1970 e 1989, R\$ 159 bilhões, ou seja, $59 \%$ do valor total, foi destinado às cooperativas do Sul. Desse montante, $\mathrm{R} \$ 83$ bilhões foram aplicados nas cooperativas gaúchas, $R \$ 63$ bilhões nas paranaenses e $\mathrm{R} \$ 8,5$ bilhões nas catarinenses. ${ }^{4}$

Nesse contexto, o centro dinâmico do cooperativismo regional era o Rio Grande do Sul, com o maior número de cooperativas e produtores e grande participação do setor na produção agropecuária e industrial. O Rio Grande do Sul abrigava, juntamente com São Paulo, as maiores cooperativas do Brasil em 1980, no caso, a Cooperativa Agrícola Central de Cotia de São Paulo (CAC) e as gaúchas Cooperativa Tritícola Serrana (COTRIJUÍ) e Central de Cooperativas de Produtores Rurais do Rio Grande do Sul (CENTRALSUL) (GAZETA MERCANTIL, 1980).

Com a recessão econômica interna nas décadas de 1980 e 1990, as cooperativas da Região Sul foram afetadas, tanto pela retração do mercado consumidor, concorrência com os produtos e empresas estrangeiras, dificuldades para exportar e rebaixamento dos preços agrícolas, como pelas reduções dos

\footnotetext{
${ }^{4}$ Valores corrigidos pelo IGP-DI de dez. 2015 (BCB, 2015).
} 
incentivos do Estado, sobretudo no crédito subsidiado, políticas de preços e aquisições de produtos.

Em todo cooperativismo brasileiro o momento foi marcado por uma profunda crise, com redução da produção e do número de associados ao ramo, desencadeando-se um movimento de falências, fusões e incorporações das cooperativas. Na Região Sul, a crise do setor ocorreu com intensidades diferentes, dependendo de diversos fatores, como a relação das cooperativas com o capital financeiro privado e público, o grau de dependência dos incentivos públicos, tipo de produção, volume de investimentos realizados e relação com o mercado interno e externo.

As cooperativas do Rio Grande do Sul foram as mais afetadas, apresentando alto número de falências, queda na produção, endividamento, redução dos ativos e do corpo social. A crise, o afastamento do Estado e os passivos, condicionaram as cooperativas gaúchas a reestruturação produtiva, comercial e gerencial nos anos noventa, todavia, sem êxito na retomada da dinâmica econômica e do crescimento demonstrado nas décadas anteriores.

No Paraná e Santa Catarina, as cooperativas também foram prejudicadas pelo contexto econômico e político dos anos oitenta e noventa, principalmente as empresas de menor porte. Nesses estados, as cooperativas mais desenvolvidas e capitalizadas tiveram maior facilidade de enfrentar o período, com estratégias de ampliação através da anexação de pequenas e médias cooperativas que estavam em dificuldade econômica e operacional.

Deste modo, até o final do século XX, as instituições do Rio Grande do Sul representavam às maiores associações da Região Sul, com maior capacidade produtiva e comercial, superando as cooperativas catarinenses e paranaenses. Porém, nas décadas de oitenta e noventa, o cenário do cooperativismo meridional inverteu e as instituições paranaenses e catarinenses assumiram o posto de maiores cooperativas regionais, consolidando-se como centro dinâmico do setor no Sul, e no Brasil, no decorrer dos anos 2000 (FARIAS, 2016).

\section{Panorama do cooperativismo agropecuário da Região Sul nos anos 2000}

Os anos 2000, diferente da década anterior, foram um período de crescimento econômico, social e espacial das cooperativas agropecuárias da Região Sul. Dentre os principais fatores que contribuíram para a expansão do setor, pode-se mencionar 
a melhora nas condições de crédito, preços e mercado doméstico e externo. Causas internas também influenciaram no desempenho das cooperativas, como a profissionalização da administração, modernização tecnológica dos produtores e das agroindústrias, investimentos produtivos e a política de retenção de sobras.

O Mapa 01 exprime a distribuição espacial das sedes das cooperativas agropecuárias da Região Sul em 2015. Com base na imagem, é possível identificar que as cooperativas localizam-se em todas as mesorregiões dos estados, mas, com maior presença no noroeste, centro-oriental e centro-ocidental do Rio Grande do Sul, oeste e sul de Santa Catarina e oeste, sudoeste e norte do Paraná. 
Mapa 01. Distribuição espacial das sedes das cooperativas agropecuárias na Região Sul do Brasil - 2015

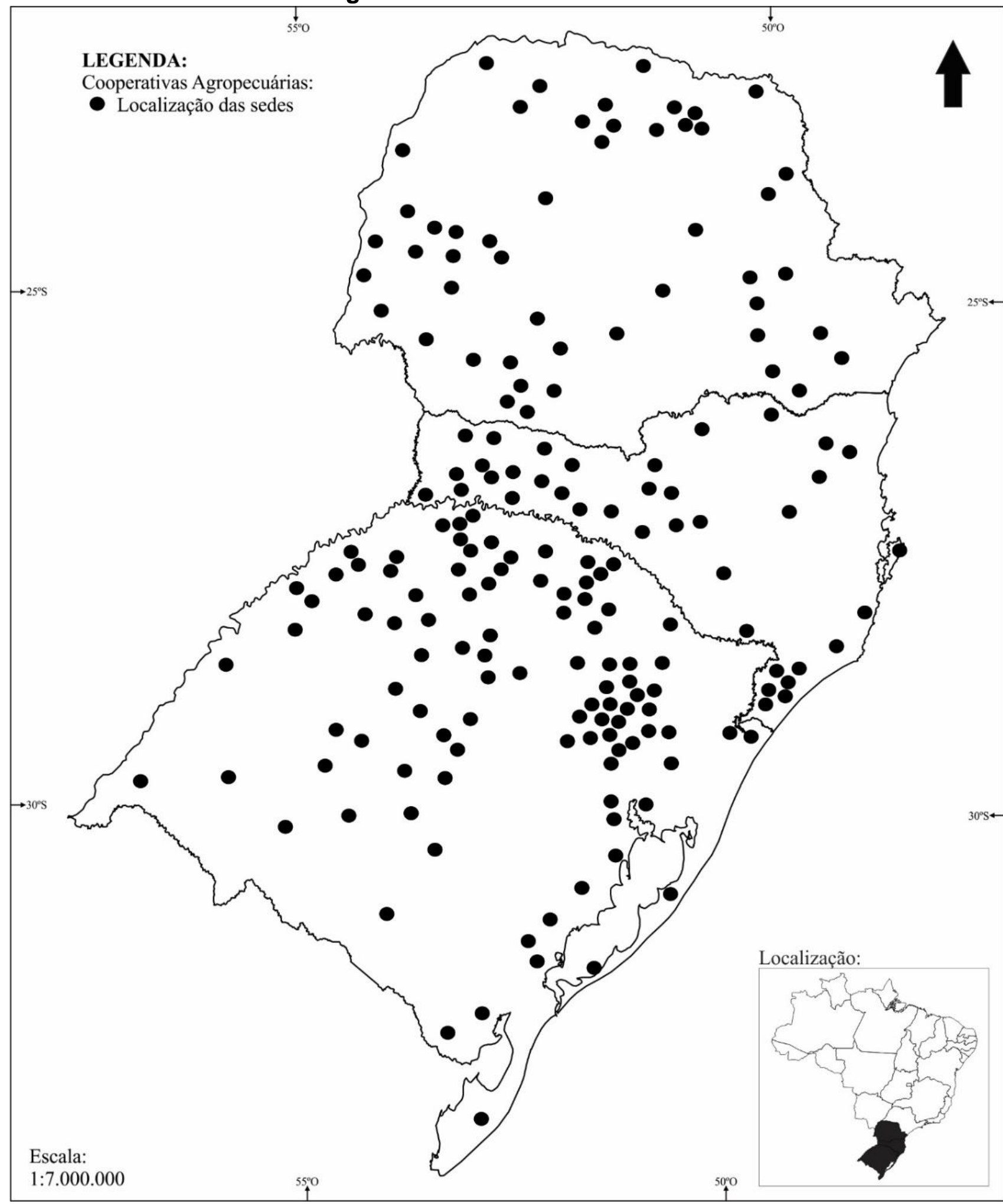

Fonte: Dados das sedes das cooperativas: OCERGS, 2016; OCESC, 2016; OCEPAR, 2016. 
É importante ressaltar que o mapa aborda apenas a localização das sedes das cooperativas e não apresenta todas as unidades do ramo. Se considerada toda a abrangência espacial do setor, poucos municípios do Sul não possuem presença direta de alguma cooperativa agropecuária. Para dimensionar a área territorial das cooperativas, somente as vinte maiores cooperativas da região estavam presentes em cerca de 450 municípios sulistas em 2015.

O mapa contribui, ainda, para demonstrar que as áreas de maior presença das cooperativas são justamente àquelas onde prevaleceu a colonização dos imigrantes europeus e japoneses na região, um indício da ligação entre o cooperativismo e FSE da pequena produção mercantil.

Com relação ao número de cooperativas, a Tabela 01 apresenta o total de associações em cada estado da Região Sul entre 2000 e 2015. Em 2015, haviam 257 cooperativas agropecuárias na região, sendo 132 no Rio Grande do Sul, 74 no Paraná e 51 em Santa Catarina.

Tabela 01. Número de cooperativas agropecuárias nos estados da Região Sul do Brasil - 2000 a 2015

\begin{tabular}{|c|c|c|c|c|c|}
\hline & PR & SC & RS & Sul & Part. $^{\mathbf{}}$ \\
\hline $\mathbf{2 0 0 0}$ & 65 & 53 & 193 & 311 & 22,0 \\
\hline $\mathbf{2 0 0 1}$ & 64 & 59 & 209 & 332 & 20,9 \\
\hline $\mathbf{2 0 0 2}$ & 68 & 59 & 196 & 323 & 19,9 \\
\hline $\mathbf{2 0 0 3}$ & 70 & 56 & 200 & 326 & 21,5 \\
\hline $\mathbf{2 0 0 4}$ & 71 & 58 & 205 & 334 & 23,9 \\
\hline $\mathbf{2 0 0 5}$ & 74 & 57 & 223 & 354 & 23,4 \\
\hline $\mathbf{2 0 0 6}$ & 77 & 54 & 237 & 368 & 23,8 \\
\hline $\mathbf{2 0 0 7}$ & 80 & 54 & 242 & 376 & 24,4 \\
\hline $\mathbf{2 0 0 8}$ & 80 & 53 & 247 & 380 & 23,6 \\
\hline $\mathbf{2 0 0 9}$ & 82 & 51 & 225 & 358 & 22,2 \\
\hline $\mathbf{2 0 1 0}$ & 80 & 53 & 211 & 344 & 22,2 \\
\hline $\mathbf{2 0 1 1}$ & 81 & 52 & 170 & 303 & 19,9 \\
\hline $\mathbf{2 0 1 2}$ & 78 & 54 & 161 & 293 & 18,8 \\
\hline $\mathbf{2 0 1 3}$ & 77 & 54 & 151 & 282 & 17,7 \\
\hline $\mathbf{2 0 1 4}$ & 74 & 53 & 140 & 267 & 17,3 \\
\hline $\mathbf{2 0 1 5}$ & 74 & 51 & 132 & 257 & 16,5 \\
\hline Médio $^{1}$ & $0,9 \%$ & $-0,1 \%$ & $-2,2 \%$ & $-1,1 \%$ & - \\
\hline Acum. $^{2}$ & $13,8 \%$ & $-3,7 \%$ & $-31,6 \%$ & $-17,3 \%$ & - \\
\hline
\end{tabular}

${ }^{1}$ Percentual de crescimento médio anual. ${ }^{2}$ Crescimento acumulado de 2000 a 2015. ${ }^{3}$ Participação da Região Sul no número de cooperativas do ramo no Brasil. Fonte: OCEPAR, 2016; OCESC, 2016; 
O número de cooperativas agropecuárias na Região Sul exibiu uma evolução negativa no período abordado, de $-17,3 \%$, com média de $-1,1 \%$ ao ano. Porém, é necessária uma visão mais abrangente do setor e da economia brasileira para a compreensão real dos dados e, após isso, é possível identificar dois momentos da recente trajetória das cooperativas: 2000 a meados de 2008, que foi um período de expansão do número de instituições regionais, de 311 para 380 e após 2008, que, em contrapartida, houve a redução para 257 cooperativas em 2015.

Os dois momentos do setor, de expansão e redução no número de cooperativas, derivaram dos movimentos econômicos internos e externos. A expansão da economia brasileira no início da década de 2000, com melhora nas condições de mercado e crédito, impulsionaram a criação de novas associações. A partir da crise financeira global de 2008, com a repentina retração dos mercados externos e diminuição da liquidez de crédito, o agronegócio brasileiro foi impactado e a redução do número de cooperativas, principalmente por processos de fusões ou aquisições, foi uma consequência do momento econômico.

No Paraná, na primeira década de 2000, o número de cooperativas cresceu de 65 para 82 em 2009 e no Rio Grande do Sul de 193 para 247 em 2008. Em 2015, o número de cooperativas paranaenses reduziu para 74 e as gaúchas foram para 132. Em Santa Catarina, houve pequenas variações no período, com o máximo de 59 cooperativas em 2002 e 2003 e o mínimo de 51 em 2009 e 2015.

Entretanto, como anunciado nas Tabela 02 e 03, o número de associados e empregados do setor na Região Sul ascendeu consecutivamente desde 2000. Tais informações indicam que, embora houvesse queda no número de cooperativas, ampliou-se o corpo social e funcional, ou seja, ocorreu um processo de expansão e concentração no cooperativismo agropecuário sulista.

O número de produtores sócios das cooperativas sulistas cresceu de 365 mil em 2000 para 548 mil em 2015, aumento de 50\%. A participação do Sul no número de sócios do ramo no Brasil engrandeceu de $44 \%$ para $54 \%$ no período, revelando que o ingresso de novos produtores ao cooperativismo foi mais intenso na região do que no restante do país - entre 2000 e 2015, o número dos associados do ramo agropecuário cresceu de 831 mil para 1 milhão. 
Tabela 02. Número de produtores associados das cooperativas agropecuárias da Região Sul do Brasil - 2000 a 2015

\begin{tabular}{|c|c|c|c|c|c|}
\hline & PR & SC & RS & Sul & Part. ${ }^{3}$ \\
\hline 2000 & 98.293 & 46.706 & 220.560 & 365.559 & 44,0 \\
\hline 2001 & 95.883 & 50.046 & 210.426 & 356.355 & 43,3 \\
\hline 2002 & 104.613 & 48.923 & 220.153 & 373.689 & 43,2 \\
\hline 2003 & 95.982 & 59.772 & 243.923 & 399.677 & 42,5 \\
\hline 2004 & 100.757 & 62.437 & 255.140 & 418.334 & 48,4 \\
\hline 2005 & 106.178 & 60.305 & 266.130 & 432.613 & 49,2 \\
\hline 2006 & 121.670 & 58.824 & 267.467 & 447.961 & 50,6 \\
\hline 2007 & 123.311 & 59.721 & 272.823 & 455.855 & 51,8 \\
\hline 2008 & 123.400 & 60.453 & 268.851 & 452.704 & 46,7 \\
\hline 2009 & 129.577 & 62.948 & 311.374 & 503.899 & 53,5 \\
\hline 2010 & 134.688 & 63.278 & 300.416 & 498.382 & 52,8 \\
\hline 2011 & 132.316 & 63.726 & 290.585 & 486.627 & 50,2 \\
\hline 2012 & 136.613 & 65.882 & 290.078 & 492.573 & 49,0 \\
\hline 2013 & 135.726 & 67.516 & 304.693 & 507.935 & 50,0 \\
\hline 2014 & 139.663 & 69.399 & 287.615 & 496.677 & 50,0 \\
\hline 2015 & 151.763 & 69.177 & 327.443 & 548.383 & 53,9 \\
\hline Médio1 & $3 \%$ & $2,8 \%$ & $2,8 \%$ & $2,8 \%$ & - \\
\hline Acum. ${ }^{2}$ & $54,4 \%$ & $48,1 \%$ & $48,4 \%$ & $50 \%$ & - \\
\hline
\end{tabular}

${ }^{1}$ Percentual de crescimento médio anual. ${ }^{2}$ Crescimento acumulado de 2000 a 2015. ${ }^{3}$ Participação da Região Sul no número de cooperados do ramo no Brasil. Fonte: OCEPAR, 2016; OCESC, 2016; OCERGS, 2016.

Dentre os estados do Sul, o Rio Grande do Sul obteve o maior número de sócios, 327 mil 2015. Entre 2000 e 2009, o número de cooperados gaúchos ampliou de 220,5 mil para 311 mil, tendo decrescido nos anos seguintes e crescendo em 2015. No Paraná, o número de produtores cooperados ampliou de 98 mil para 151,7 mil e em Santa Catarina de 46,7 mil para 69 mil.

Os percentuais de expansão em cada estado foram semelhantes: crescimento médio anual foi de $3 \%$ no Paraná e de $2,8 \%$ nos demais e o crescimento acumulado no período foi 54\% no Paraná e 48\% em Santa Catarina e Rio Grande do Sul. 
Tabela 03. Número de empregados das cooperativas agropecuárias da Região Sul do Brasil - 2000 a 2015

\begin{tabular}{|c|c|c|c|c|c|}
\hline & PR & SC & RS & Sul & Part. $^{3}$ \\
\hline 2000 & 28.460 & 10.044 & 24.473 & 62.977 & 58,2 \\
\hline 2001 & 29.086 & 10.381 & 24.523 & 63.990 & 59,1 \\
\hline 2002 & 29.946 & 12.015 & 24.827 & 66.788 & 63,2 \\
\hline 2003 & 30.038 & 12.212 & 26.273 & 68.523 & 61,8 \\
\hline 2004 & 36.627 & 13.848 & 26.096 & 76.571 & 65,5 \\
\hline 2005 & 45.447 & 15.346 & 26.096 & 86.889 & 70,4 \\
\hline 2006 & 44.410 & 15.433 & 26.621 & 86.464 & 69,8 \\
\hline 2007 & 45.529 & 18.181 & 35.586 & 99.296 & 71,1 \\
\hline 2008 & 48.444 & 20.618 & 28.957 & 98.019 & 72,8 \\
\hline 2009 & 53.148 & 20.969 & 28.611 & 102.728 & 74,0 \\
\hline 2010 & 54.807 & 22.359 & 27.435 & 104.601 & 71,6 \\
\hline 2011 & 53.439 & 24.580 & 27.330 & 105.349 & 67,6 \\
\hline 2012 & 56.076 & 27.660 & 29.687 & 113.423 & 69,1 \\
\hline 2013 & 65.000 & 31.809 & 28.888 & 125.697 & 76,5 \\
\hline 2014 & 67.035 & 34.637 & 31.120 & 132.792 & 73,4 \\
\hline 2015 & 69.525 & 38.111 & 33.282 & 140.918 & 74,6 \\
\hline Médio' & $6,4 \%$ & $9,4 \%$ & $2,5 \%$ & $5,6 \%$ & - \\
\hline Acum. ${ }^{2}$ & $144,3 \%$ & $279,4 \%$ & $35,9 \%$ & $123,7 \%$ & - \\
\hline
\end{tabular}

${ }^{1}$ Percentual de crescimento médio anual. ${ }^{2}$ Crescimento acumulado de 2000 a 2015 . ${ }^{3}$ Participação da Região Sul no número de empregados do ramo no Brasil. Fonte: OCEPAR, 2016; OCESC, 2016; OCERGS, 2016.

Referindo-se ao número de empregados do setor na região, ampliou de 62,9 mil em 2000 para 140,9 mil em 2015, alta de 123\%. A participação das cooperativas do Sul nos trabalhadores do ramo em nível nacional também avolumou, de $58 \%$ para $74 \%$. O Paraná ostentou o maior número de trabalhadores em cooperativas, 69,5 mil em $2015,144 \%$ a mais que em 2000 , que era de 28,4 mil trabalhadores.

O cooperativismo de Santa Catarina registrou 38 mil empregados e no Rio Grande do Sul foram 33 mil. Percentualmente, as cooperativas catarinenses portaram o melhor desempenho, de $9,4 \%$ no crescimento médio anual e $279 \%$ no crescimento acumulado.

Ao passo que as empresas cooperativas paranaenses e catarinenses mantiveram expansão dos empregados nos pós-2008, no Rio Grande do Sul houveram várias quedas nos números de empregados nesse contexto. A menor 
quantidade de empregos nas associações gaúchas expõe sua baixa inserção na produção agroindustrial, quando comparado aos demais estados sulistas.

O conjunto de dados sobre a evolução no número de instituições, sócios e empregados do cooperativismo agropecuário na Região Sul do Brasil permite as seguintes afirmações:

A despeito dos impactos gerados pela crise de 2008, que reduziram o número de unidades cooperativas, o número de sócios e empregados manifestou evolução positiva no período, isso devido ao fato de muitos produtores associarem-se as cooperativas como medida de proteção com relação ao período de recessão.

É importante lembrar que, entre 2010 e 2015, ocorreu maior oferta de crédito oficial para investimentos em agroindustrialização e armazenagem em cooperativas. $\mathrm{Na}$ medida que o setor investiu na verticalização de diferentes cadeias do agronegócio, cresceu o número de produtores e empregados no cooperativo, principalmente nas cadeias produtivas de aves, suínos, lácteos e grãos.

Já a retração do número de cooperativas a partir de 2008, foi uma alternativa ao panorama econômico e financeiro imposto pela crise internacional, com acirramento da concorrência pela produção, crédito e mercado em todo o agronegócio nacional. Diante disso, ocorreu o advento de cooperativas cada vez maiores, com maior número de produtores associados e empregados, acumulando maior capacidade financeira e de produção. Exemplificando, o número médio de sócios por cooperativa na Região Sul em 2000 era de 1,1 mil por cooperativa e, em 2015, subiu para 2,1 mil. No caso dos empregados, a média era de 202,5 mil por cooperativa em 2000 e foi para 548,3 por cooperativa em $2015 .{ }^{5}$

O processo de concentração do cooperativismo agropecuário vem ocorrendo em todas as regiões do país, mas, nos estados do Sul tem sido mais intenso. Entre 2000 e 2015, no Paraná o número de empregados por cooperativa dilatou de 438 para 939, em Santa Catarina ampliou de 189 para 747 e no Rio Grande do Sul de 127 para 252. No tocante aos sócios por cooperativa, avolumaram de 1.512 para

\footnotetext{
${ }^{5}$ Questionado sobre a diminuição no número de cooperativas em 2010 e 2011, o Presidente a OCB Organização das Cooperativas Brasileiras, Márcio Lopes de Freitas, respondeu: Ou fecham ou acabam incorporadas por outras cooperativas. Vem acontecendo uma consolidação no setor. $\mathrm{Na}$ disputa pelo mercado, a cooperativa funciona igual a uma empresa mercantil. A única diferença é que ela tem uma organização societária diferente. Porém, apesar da redução do número de cooperativas no Brasil, o número de associados vem aumentando e sua participação das no mercado agrícola também aumentou. Há alguns anos, elas respondiam por $40 \%$ da produção agrícola nacional e hoje essa fatia aumentou para $46 \%$. O mercado brasileiro conta com dez milhões de sócios em todos os 13 ramos, dos quais, 970 mil em cooperativas agrícolas, que empregam 156 mil pessoas (DINHEIRO RURAL, 2012).
} 
2.051 no Paraná, de 881 para 1.356 em Santa Catarina e de 1.143 a 2.480 no Rio Grande do Sul. ${ }^{6}$

Prosseguindo com o estudo do panorama do cooperativismo rural sulista nos anos 2000, as Tabelas 04 aborda a produção agropecuária das cooperativas na Região Sul no intervalo de 2000 e 2015.

Tabela 04. Produção agropecuárias das cooperativas na Região Sul do Brasil 2000 a 2015

\begin{tabular}{|c|c|c|c|c|c|c|c|c|c|}
\hline & \multicolumn{3}{|c|}{ PR } & \multicolumn{3}{c|}{ SC } & \multicolumn{3}{c|}{ RS } \\
\hline & $\mathbf{2 0 0 0}$ & $\mathbf{2 0 1 5}$ & Cresc. & $\mathbf{2 0 0 0}$ & $\mathbf{2 0 1 5}$ & Cresc. & $\mathbf{2 0 0 0}$ & $\mathbf{2 0 1 5}$ & Cresc. \\
\hline Soja & 4,6 & 12,0 & $161 \%$ & 0,3 & 1,0 & $233 \%$ & 2,8 & 5,7 & $104 \%$ \\
\hline Milho & 2,5 & 10,5 & $320 \%$ & 0,66 & 1,5 & $127 \%$ & 1,7 & 0,8 & $-53 \%$ \\
\hline Trigo & 1,19 & 2,0 & $68 \%$ & 0,06 & 0,33 & $450 \%$ & 0,7 & 1,17 & $67 \%$ \\
\hline Aves & 0,26 & 1,37 & $427 \%$ & 0,17 & 0,53 & $212 \%$ & - & - & - \\
\hline Suínos & 0,05 & 0,26 & $420 \%$ & 0,13 & 0,41 & $215 \%$ & - & - & - \\
\hline Leite & 582 & 1.216 & $165 \%$ & 211 & 560 & $109 \%$ & - & 1.700 & - \\
\hline
\end{tabular}

Produção de Leite em Milhões de Litros. Fonte: OCEPAR, 2016; OCESC, 2016, FECOAGRO/RS, 2016.

As cooperativas paranaenses tiveram o maior volume de produção agrícola recebida, com ressalto para a soja e o milho. A produção de soja recebida pelo setor aumentou de 4,65 milhões de toneladas em 2000 para 12 milhões de toneladas em 2015, diferença de $161 \%$ e o milho teve expansão de 2,5 milhões de toneladas para 10,5 milhões de toneladas, avanço de $320 \%$. Com relação a produção de trigo, as cooperativas estaduais amplificaram de 1,19 milhão de toneladas para 2 milhões de toneladas, progresso de $68 \%$.

Na pecuária, as associações paranaenses destacaram-se no recebimento de leite e no abate de aves e suínos. Em 2000, o abate de aves do setor era de 261 mil toneladas e aumentou para 1,3 milhões de toneladas em 2015 e o abate de suínos cresceu de 53 mil toneladas para 268 mil toneladas. Nesses dois produtos, as cooperativas lograram os maiores crescimentos percentuais no período, de $427 \%$ e $420 \%$. A produção de leite expandiu de 581 milhões de litros para 1,2 bilhões de litros, $165 \%$.

Em Santa Catarina, os suínos e as aves foram os principais produtos das cooperativas. O abate de suínos avultou de 139 mil toneladas em 2000 para 411 mil toneladas em 2015, referente a 1,6 milhão de cabeças para 4,8 milhões de cabeças cresceu de 589 por cooperativa em 2000 para 654 sócios por cooperativa em 2015 (OCB, 2016). 
de suínos, respectivamente. O abatimento de aves alterou de 173 mil toneladas para 538 mil toneladas, que equivaleu a produção de 69 milhões de frango em 2000 e 215 milhões em 2015.

No Rio Grande do Sul, as cooperativas ressaltaram-se na produção de soja, com aumento de 2,8 milhões de toneladas em 2000 para 5,7 milhões de toneladas em 2015 e leite, com 1,7 milhões de litros produzidos em 2015. O recebimento de milho das cooperativas registrou queda no período observado, de 1,7 milhões de toneladas para 860 mil toneladas, ou seja, redução de $53 \%$ no recebimento do produto.

O trigo, que historicamente foi produto mais importante do cooperativismo gaúcho, teve uma alta $67 \%$ no ínterim, de 742 mil toneladas para 1,17 milhão de toneladas

A Tabela 05 ilustra a participação das cooperativas na produção agropecuário nos estados sulistas em 2000 e 2015.

Tabela 05. Participação das cooperativas na produção agropecuárias da Região Sul do Brasil - 2000 a 2015

\begin{tabular}{|c|c|c|c|c|c|c|}
\hline & \multicolumn{2}{|c|}{ PR } & \multicolumn{2}{c|}{ SC } & \multicolumn{2}{c|}{ RS } \\
\hline & $\mathbf{2 0 0 0}$ & $\mathbf{2 0 1 5}$ & $\mathbf{2 0 0 0}$ & $\mathbf{2 0 1 5}$ & $\mathbf{2 0 0 0}$ & $\mathbf{2 0 1 5}$ \\
\hline Soja & $65 \%$ & $70 \%$ & $58 \%$ & $50 \%$ & $41 \%$ & $35 \%$ \\
\hline Milho & $34 \%$ & $65 \%$ & $20 \%$ & $49 \%$ & $29 \%$ & $18 \%$ \\
\hline Trigo & $79 \%$ & $64 \%$ & $121 \%$ & $252 \%$ & $69 \%$ & $46 \%$ \\
\hline Aves & $27 \%$ & $34 \%$ & $11 \%$ & $24 \%$ & - & - \\
\hline Suínos & $15 \%$ & $40 \%$ & $21 \%$ & $47 \%$ & - & - \\
\hline Leite & $57 \%$ & $45 \%$ & $21 \%$ & $24 \%$ & - & $45 \%$ \\
\hline
\end{tabular}

Produção de Leite em Milhões de Litros. Fonte: OCEPAR, 2016; OCESC, 2016, FECOAGRO/RS, 2016.

A respeito da participação das cooperativas da produção agropecuária de cada estado, as instituições do Paraná demonstraram as melhores performances, chegando a representar $70 \%$ da soja produzida no estado, $65 \%$ do milho e $64 \%$ do trigo em 2015. Os produtos com maior expansão produtiva do ramo no estado foram o milho, de $34 \%$ para $65 \%$ e suínos, de $15 \%$ para $40 \%$. Na produção de trigo e leite, as cooperativas paranaenses perderam participação.

Em Santa Catarina, o cooperativismo alcançou importantes participações na produção de soja, milho e suínos, que abrangeram cerca de $50 \%$ das produções estaduais em 2015. No trigo, devido a originação de produto fora do estado, a 
produção das cooperativas superou a produção catarinense. Os produtos com maior ganho de participação das cooperativas foram aves, de $11 \%$ para $24 \%$, suínos, de $21 \%$ para $47 \%$ e milho, de $20 \%$ para $49 \%$.

A participação do cooperativismo na produção de grãos do Rio Grande do Sul reduziu no período, de $41 \%$ para $35 \%$ na soja, $29 \%$ para $18 \%$ no milho e $39 \%$ para $46 \%$ no trigo. No leite, as cooperativas gaúchas somaram parcela importante na produção estadual, 45\% em 2015.

Um dos indicadores mais pertinentes sobre a nova dinâmica econômica e produtiva das cooperativas do sul do país foram as exportações e a integração ao mercado global de alimentos, que, entendido de outra forma, permite notar o engrandecimento da capacidade produtiva, de armazenagem e de agregação de valor do setor.

O Gráfico 01 revela as exportações das cooperativas dos estados do Sul de 2006 a 2015. Nesses anos, as exportações do cooperativismo brasileiro somaram US \$ 47 bilhões e as vendas das cooperativas agropecuárias regionais foram de US\$ 22 bilhões, correspondendo a $46 \%$ das exportações totais do ramo no país.

\section{Gráfico 01. Exportações das cooperativas agropecuárias da Região Sul do Brasil - 2006 a 2015}

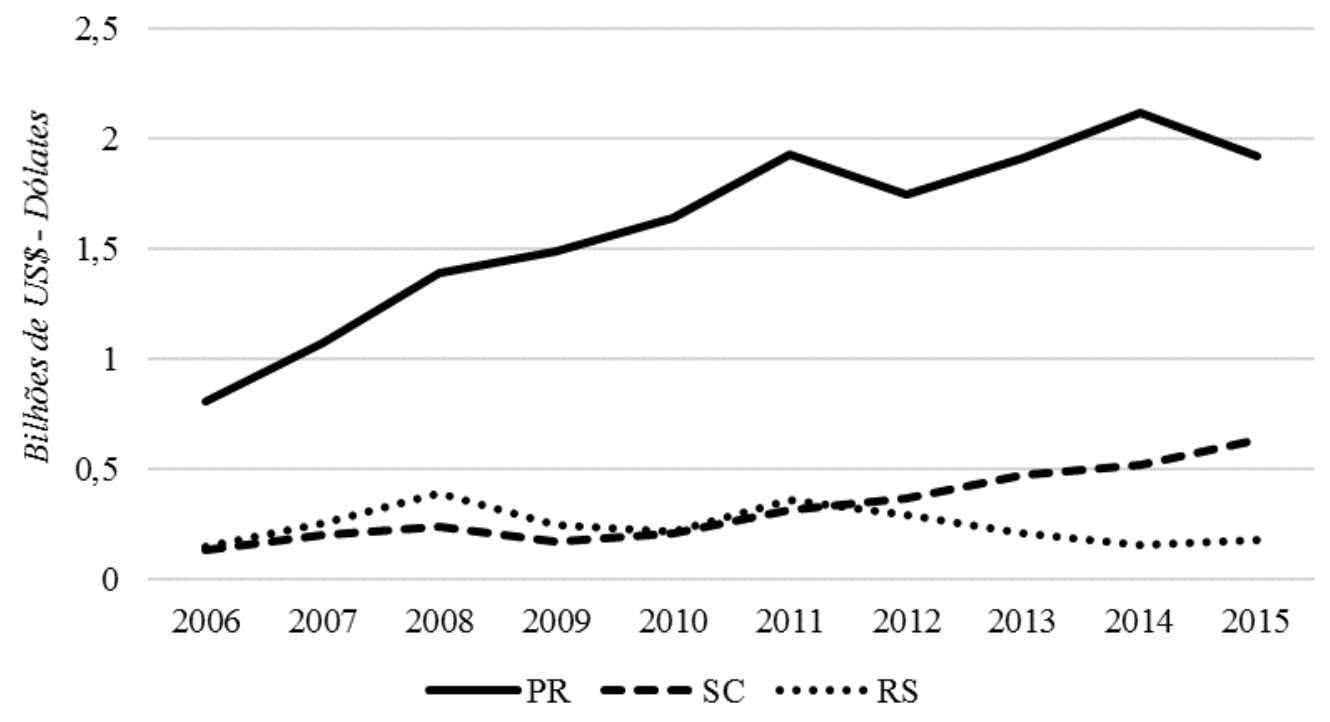

Fonte: MDIC, 2006 a 2015.

Os anos 2000 podem ser considerados como um marco nas exportações das cooperativas agropecuárias brasileiras e meridionais. No início do século XXI, as 
cooperativas traçaram uma linha ascendente nas vendas externas, diversificando os mercados e produtos exportados. Nesse contexto, mudanças políticas e econômicas internas, como os incentivos fiscais, desvalorização cambial e melhoras nos mecanismos de crédito para empresas exportadoras, impulsionaram as vendas externas do setor.

No Sul, as cooperativas do Paraná detiveram o melhor desempenho nas exportações, com US\$ 16 bilhões, o que significou $73 \%$ das exportações do cooperativismo regional e $34 \%$ do ramo nacional. O valor exportado cresceu de US\$ 800 milhões em 2006 para US\$1,9 bilhão em 2015, evolução média de $11 \%$ ao ano e alta de $140 \%$ em 2015 comparado com 2006. O ano com maior exportação das cooperativas paranaenses foi em 2014 com US $\$ 2,1$ bilhões.

Santa Catarina participou com $15 \%$ das exportações regionais e $7 \%$ das nacionais, tendo US $\$ 3,2$ bilhões em vendas e variação de 377\% entre 2006 e 2015, com média de $21 \%$ ao ano. Em valores, as exportações subiram de US\$ 132 milhões para US\$ 634 milhões. É interessante assinalar que, desde 2009, as cooperativas catarinenses foram as únicas em âmbito nacional que sustentaram acréscimos nos valores exportados.

As cooperativas do Rio Grande do Sul comercializaram US\$2,4 bilhões, 11\% das vendas regionais e $5,2 \%$ das vendas totais do ramo. Apensar de possuir variação de $9,3 \%$ ao ano nas exportações, as cooperativas gaúchas mostraram um crescimento acumulado de apenas $20 \%$ de 2006 a 2015. Foi nítida a desaceleração das exportações das cooperativas gaúchas, que em 2008 exportaram US\$391 milhões, US $\$ 363,5$ milhões em 2011 e $\mathrm{R} \$ 158,9$ milhões em 2014, quase o mesmo montante que em 2006, de US\$ 147 milhões.

Enquanto no Paraná os principais produtos exportados pelas cooperativas foram a soja e derivados e carne de frango, em Santa Catarina o maior volume foi de carne de aves e suínos e no Rio Grande do Sul foi soja e derivados.

Por fim, a Tabela 06 expressa o faturamento das cooperativas em cada estado da Região Sul de 2000 a 2015. Os valores referem-se as receitas brutas do setor no período e contribuem na avaliação da recente dinâmica geoeconômica do cooperativismo agropecuário meridional. 
Tabela 06. Faturamento bruto das cooperativas agropecuárias nos estados da Região Sul do Brasil - 2000 a 2015

\begin{tabular}{|c|c|c|c|c|c|c|c|}
\hline & \multicolumn{2}{|c|}{ PR } & \multicolumn{2}{c|}{ SC } & \multicolumn{2}{c|}{ RS } & Total \\
\hline $\mathbf{2 0 0 0}$ & 5,7 & $\%^{3}$ & 1,9 & $\%^{3}$ & - & $\%^{3}$ & 7,65 \\
\hline $\mathbf{2 0 0 1}$ & 7,0 & $21,6 \%$ & 2,3 & $20,4 \%$ & - & - & 9,29 \\
\hline $\mathbf{2 0 0 2}$ & 9,9 & $42,3 \%$ & 2,9 & $23,9 \%$ & - & - & 12,79 \\
\hline $\mathbf{2 0 0 3}$ & 13,6 & $37,3 \%$ & 3,6 & $28,0 \%$ & - & - & 17,28 \\
\hline $\mathbf{2 0 0 4}$ & 16,3 & $19,9 \%$ & 4,5 & $22,0 \%$ & - & - & 20,80 \\
\hline $\mathbf{2 0 0 5}$ & 14,3 & $-12,7 \%$ & 4,7 & $6,6 \%$ & - & - & 19,02 \\
\hline $\mathbf{2 0 0 6}$ & 14,1 & $-0,9 \%$ & 4,7 & $-0,6 \%$ & - & - & 18,86 \\
\hline $\mathbf{2 0 0 7}$ & 16,8 & $19,0 \%$ & 5,9 & $24,7 \%$ & - & - & 22,71 \\
\hline $\mathbf{2 0 0 8}$ & 22,4 & $33,1 \%$ & 7,3 & $23,8 \%$ & - & - & 29,67 \\
\hline $\mathbf{2 0 0 9}$ & 21,1 & $-5,8 \%$ & 7,2 & $-0,6 \%$ & - & - & 28,33 \\
\hline $\mathbf{2 0 1 0}$ & 21,7 & $2,9 \%$ & 7,8 & $7,7 \%$ & 14,9 & - & 44,40 \\
\hline $\mathbf{2 0 1 1}$ & 26,6 & $22,6 \%$ & 9,4 & $20,6 \%$ & 15,1 & $1,3 \%$ & 51,12 \\
\hline $\mathbf{2 0 1 2}$ & 32,3 & $21,6 \%$ & 11,1 & $18,2 \%$ & 15,8 & $4,6 \%$ & 59,28 \\
\hline $\mathbf{2 0 1 3}$ & 38,6 & $19,3 \%$ & 13,0 & $17,2 \%$ & 18,7 & $18,4 \%$ & 70,34 \\
\hline $\mathbf{2 0 1 4}$ & 42,2 & $9,3 \%$ & 15,1 & $15,8 \%$ & 19,9 & $6,4 \%$ & 77,20 \\
\hline $\mathbf{2 0 1 5}$ & 56,5 & $33,9 \%$ & 17,1 & $13,1 \%$ & 22,1 & $11,1 \%$ & 95,67 \\
\hline Total & 359,2 & - & 118,6 & - & 106,5 & - & 584,30 \\
\hline Médio ${ }^{1}$ & - & $17,6 \%$ & - & $16,0 \%$ & - & $8,4 \%$ & - \\
\hline Acum. ${ }^{2}$ & - & $884 \%$ & - & $794 \%$ & - & $48,3 \%$ & - \\
\hline
\end{tabular}

Valores em Bilhões de R $\$$ correntes. ${ }^{1}$ Percentual de crescimento médio anual. ${ }^{2}$ Crescimento acumulado de 2000 a 2015. ${ }^{3}$ Crescimento percentual anual. Fonte: OCEPAR, 2016; OCESC, 2016; OCERGS, 2016.

Entre 2000 e 2015, as receitas das cooperativas agropecuárias exibidas na tabela somaram $\mathrm{R} \$ 584$ bilhões. Somente entre 2010 e 2015, o faturamento do setor cresceu de $R \$ 44,4$ bilhões para $R \$ 95,6$ bilhões, ou seja, variação de $115 \%$ em cinco anos. As cooperativas paranaenses evidenciaram as maiores rendas, $R \$ 56,5$ bilhões em 2015 , $884 \%$ a mais que seus $R \$ 5,7$ bilhões de 2000 . As cooperativas do estado acumularam $R \$ 359$ bilhões de 2000 a 2015, com expansão média de 17,6\% ao ano.

Em Santa Catarina, o faturamento das cooperativas subiu de $R \$ 1,9$ bilhão em 2000 para R $\$ 17$ bilhões em 2015, com média de 16\% ao ano. No Rio Grande do Sul, com dados apenas de 2010 a 2015 , as receitas oscilaram em média $8,4 \%$ ao ano, de $R \$ 15$ bilhões à $R \$ 22$ bilhões 
Apesar das cooperativas gaúchas possuírem maior expressão no número de cooperativas e sócios, no desempenho econômico elas foram inferiores às paraenses e catarinenses, uma vez que Santa Catarina possuiu menos da metade do número de cooperativas gaúchas e um quinto do número de sócios, mas com faturamento anual equivalente ao cooperativismo rio-grandense. Em média, o faturamento por cooperativa em 2015 foi de $R \$ 763$ milhões no Paraná, $R \$ 335$ milhões em Santa Catarina e R\$167 milhões no Rio Grande do Sul.

As cooperativas do Paraná e de Santa Catarina, em especial do oeste do estado, exibiram, desde o final da década de noventa, maior capacidade promover uma reestruturação produtiva e comercial, com a modernização e profissionalização na gestão, melhorando a administração dos ativos e passivos, investindo em cadeias agroindustriais e expandindo as áreas de atuação, inclusive para estados de outras regiões e outros países. ${ }^{7}$ Muitas cooperativas gaúchas, inclusive as tradicionais instituições que nos anos 1970 estavam entre as maiores do Brasil, expressaram problemas financeiros, com endividamento, e de produção, com capacidade ociosa, nos últimos anos. ${ }^{8}$

Em 2015, das vinte maiores cooperativas agropecuárias da Região Sul, quatorze eram do Paraná - Coamo, C.Vale, Lar, Cocamar, Copacol, Agrária, Integrada, Castrolanda, Coopavel, Frimesa, Frísia, Copagril, Coasul e Capal; três gaúchas - Cotrijal, Cotrisal e Languiru e três de Santa Catarina - Aurora, Cooperalfa e Coopercampos. Essa composição, bem diferente daquela dos anos setenta e oitenta, denota as diferentes trajetórias das cooperativas dos estados sulistas e o agigantamento do ramo paranaense perante os demais estados.

\section{Considerações Finais}

Nos anos 2000, as cooperativas voltaram a crescer com ampliação das instituições, sócios, empregados, faturamento, exportação e produção agropecuária e agroindustrial. O progresso do setor ocorreu em todas as regiões do Brasil, porém,

\footnotetext{
${ }^{7}$ A Coamo, Aurora, Cooperalfa, C.Vale, Lar, Cocamar, Frísia, Castrolanda, por exemplo, expandiram sua área de atuação para outras regiões no decorrer dos anos 2000, especialmente no Mato Grosso, Mato Grosso do Sul e São Paulo. A C.Vale e Lar ampliaram suas atividades de recebimento e armazenagem de grãos no Paraguai e a Agrária adquiriu uma empresa de comércio de cereais no Uruguai.

${ }^{8}$ Em 2018, a Cotrijuí, de ljuí/RS, entrou em processo de liquidação judicial. A cooperativa, que já foi a maior da América Latina, acumula dívidas de $R \$ 1,8$ bilhão, quase o dobro de seu patrimônio total (GAUCHAZH, 2018).
} 
no Sul manifestou o seu maior dinamismo. As cooperativas sulistas dispuseram do apoio público para investimentos produtivos e adotaram estratégias que as permitiram crescer, nos anos recentes, com integração industrial.

A expansão do agronegócio cooperativo regional a partir de 2000 compreendeu uma nova fase de desenvolvimento do setor, contraponto o período de crise do ramo nas décadas de 1990 e 1980. A retomada do crescimento geoeconômico das cooperativas foi constatada na evolução dos principais indicadores do setor número de instituições, sócios, empregados, faturamento e produção - que, além apurar sobre a ascensão do cooperativismo no Sul, propiciou averiguar as características da trajetória em cada estado.

Diante dos dados estatísticos expostos no texto, pode-se inferir as seguintes considerações sobre a expansão do cooperativismo agropecuário sulista após 2000:

As cooperativas gaúchas, que até a década de oitenta representavam o que havia de mais dinâmico no cooperativismo regional, no processo de retomada do crescimento nos anos 2000, mostraram um desempenho econômico inferior às cooperativas paranaenses e catarinenses, uma vez que essas foram mais capazes de promover sua reestruturação produtiva e comercial.

O Rio Grande do Sul, que foi onde o cooperativismo surgiu na região e igualmente o local de gênese do cooperativismo empresarial na década de 1950, enfrentou maiores complicações durante o período de crise nas décadas de oitenta e noventa e demonstrou maior dificuldade na realização da reestruturação econômica e produtiva, em geral devido aos problemas financeiros.

Outros dados que reforçam a hipótese de que o Paraná e Santa Catarina simbolizaram, ao longo dos anos 2000, o centro mais dinâmico do agronegócio cooperativo no Sul e no Brasil, foram as multiplicações na produção agroindustrial e exportações e as maiores contratações de capital externo nas cooperativas desses estados, principalmente de crédito público. A destacada expansão geoeconômica de algumas cooperativas paranaenses e catarinenses assegurou-Ihes a elevação ao patamar de grandes empresas do agronegócio brasileiro.

Dessarte, o estudo do cooperativismo se insere na compreensão mais ampla da dinâmica do agronegócio brasileiro, sendo elas capazes de concorrer diretamente com gigantes empresas internacionais que atuam no setor agroindustrial. A cooperativização foi a forma encontrada em uma expertise empresaria nacional para se inserir e se manter em um mercado cada vez mais oligopolizado. 


\section{Referências}

ALVES, André Gustavo de Miranda Pineli. As cooperativas agropecuárias e o BRDE - Histórico, Situação Atual e Perspectivas. Diretoria de Planejamento, BRDE, nov. 2003.

BENETTI, Maria Domingues. Endividamento e crise no cooperativismo empresarial do Rio Grande do Sul: Análise do caso FECOTRIGO/CENTRALSUL - 1974-83. Ensaios FEE, Porto Alegre/RS, v. 6, nํ. 2, p. 23-55, 1985.

BENETTI, Maria Domingues. Origem e formação do cooperativismo empresarial no Rio Grande do Sul: Uma análise do desenvolvimento da COTRIJUí,

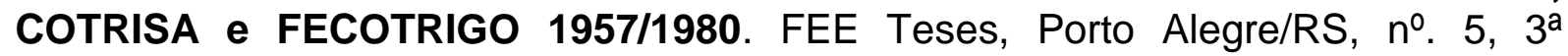
impressão, set. 1992. 171 p.

CORADINI, Odacir Luiz; FREDERICQ, Antoinette. Agricultura, cooperativas e multinacionais. Coleção Agricultura e Sociedade, ZAHAR Editores, Rio de Janeiro, 1982. $184 \mathrm{p}$.

DELGADO, Guilherme Costa. Capital Financeiro e Agricultura no Brasil: 19651985. São Paulo: Unicamp/Ícone, 1985. 237 p.

DENACOOP. Evolução do cooperativismo no Brasil. Ministério da Agricultura, Pecuária e Abastecimento (MAPA), Brasília, 2006. 124 p. Disponível em: $<$ http://www.agricultura.gov.br/assuntos/cooperativismo-associativismo/arquivos-

publicacoes-cooperativismo/evolucao-do-cooperativismo-no-brasil.pdf/view $>$. Acesso em: 05 dez. 2018.

DINHEIRO RURAL. Entrevista Marcio Lopes de Freitas. Revista Dinheiro Rural, no 98, Edição 01/12/2012. Disponível em: $<$ https://www.dinheirorural.com.br/secao/entrevista/entrevista-marcio-lopes-defreitas >. Acesso em: 07 jan. 2016.

EW, Aní Reni. Reestruturação do cooperativismo agropecuário no Rio Grande do Sul: estudos de caso - década de 90. 2001. Dissertação (Mestrado) - Curso de Economia Rural, PGDR/UFRGS, Porto Alegre, 2001.

FARIAS, Fernando. A dinâmica geoeconômica do cooperativismo agropecuário do Sul do Brasil. 2015. 327 f. Tese (Doutorado) - Curso de Geografia, PPGGUFSC, Florianópolis, 2015.

FARIAS, Fernando; ESPÍNDOLA, Carlos José. O cooperativismo agropecuário do Sul do Brasil a partir da conjuntura econômica dos anos 1980: alteração territorial de seu centro dinâmico. GEOSUL, Florianópolis/SC, v.31, nํ. 61, p. 3366, jan./jun. de 2018.

FECOAGRO/RS. Federação das Cooperativas Agropecuárias do Estado do Rio Grande do Sul. 2016. Disponível em: <https://www.fecoagrors.com.br/>. Acesso em: 07 jan. 2018.

FLEURY, Maria Tereza Leme. Cooperativas agrícolas e capitalismo no Brasil. Teses 11, São Paulo: Ed. Global, 1983. 152 p.

IPARDES. Cooperativas de produção agropecuária no Paraná. Curitiba/PR: Diagnóstico e analises, 1974. 535 p. 
GAUCHAZH. Cotrijui: de ícone do agronegócio à liquidação judicial. 02/02/2018. Disponível em :<https://gauchazh.clicrbs.com.br/economia/campo-elavoura/noticia/2018/02/cotrijui-de-icone-do-agronegocio-a-liquidacao-judicialcjd67aq3n06i601phrz7aakzv.html>. Acesso em: 12 mar. 2018.

GAZETA MERCANTIL. Balanço Anual. São Paulo: Editora Jornalística Gazeta Mercantil, 1980.

GLOBO RURAL. Cooperativas pedem passagem. Editora Globo, São Paulo, Ano $18, n^{\circ} .213$, jul. 2003.

GONÇALVES, José Sidnei. Capitalismo e cooperativismo na agricultura. Relatório de Pesquisa do Instituto de Economia Agrícola, São Paulo, 1987. 47 p.

GONÇALVES, José Sidnei; VEGRO, Celso Luis R. Crise econômica e cooperativismo agrícola: Uma discussão sobre os condicionantes das dificuldades financeiras da Cooperativa Agrícola de Cotia (CAC). Agricultura em São Paulo, São Paulo, v. 41, no. 2, p. 57-87, 1994.

LOUREIRO, Maria Rita Garcia (Org.). Cooperativas agrícolas e capitalismo no Brasil. São Paulo: Cortez, 1981. 155 p. (Coleção teoria e práticas sociais)

MDIC - Ministério do Desenvolvimento Indústria e Comércio Exterior. Estatísticas do comércio exterior. Vários anos.

MORASCO, Fernanda. O cooperativismo de crédito em Santa Catarina. Monografia, Departamento de Ciências Econômicas, Universidade Federal de Santa Catarina (UFSC). Florianópolis/SC, ago. 2007.

NETO, Sigismundo Bialoskorski. Tendências do cooperativismo agropecuário no mundo e os desafios para o Brasil. Especial Cooperativismo, OCB, p. 24-26, jul. 2009.

Disponível

em:

$<$ http://bibliotecadigital.fgv.br/ojs/index.php/agroanalysis/article/viewFile/26881/25754

>. Acesso em: 10 jan. 2019.

NINAUT, Evandro Scheidt; MATOS, Marcos Antonio. Panorama do cooperativismo no Brasil: censo, exportações e faturamento. Informações Econômicas, São Paulo, v. 38, ํ․ . 8, p. 43-55, ago. 2008.

OCB - Organização das Cooperativas Brasileiras. Brasília/DF. Disponível em: <http://www.ocb.org.br>. Acesso em: 01 nov. 2018.

OCEPAR - Organização das Cooperativas do Estado do Paraná. Curitiba/PR. Disponível em: <http://www.ocepar.org.br>. Acesso em: 30 nov. 2018.

OCERGS. Organização das Cooperativas do Estado do Rio Grande do Sul. Porto Alegre/RS. Disponível em: <http://www.ocergs.org.br>. Acesso em: 30 nov. 2018.

OCESC. Organização das Cooperativas do Estado de Santa Catarina. Florianópolis/SC. Disponível em: <http://www.ocesc.org.br>. Acesso em: 05 dez. 2018.

PADILHA, Wilian. O papel do crédito no desenvolvimento das cooperativas agropecuárias. 2014. 230 f. Dissertação (Mestrado) - Curso de Geografia, Programa de Pós-Graduação em Geografia, PPGG/UNIOESTE, Francisco Beltrão/PR, fevereiro de 2014. 
UNIRCOOP. Panorama do cooperativismo brasileiro: história, cenários e tendências. Rede de Universidades das Américas para Estudos Cooperativos e Associativos, 2003. 55 p.

VALOR ECONÔMICO. Valor 1000.1 Vários anos. <https://www.valor.com.br/valor1000/>. Acesso em: 10 dez. 2018. 


\section{NOTAS DE AUTOR}

\section{CONTRIBUIÇÃO DE AUTORIA}

Wilian Padilha - Concepção e elaboração do manuscrito. Coleta de dados e análise de dados. Revisão e aprovação da versão final do trabalho.

Fernando dos Santos Sampaio - Concepção e elaboração do manuscrito. Participação ativa da discussão dos resultados. Revisão e aprovação da versão final do trabalho.

\section{FINANCIAMENTO}

Não se aplica.

\section{CONSENTIMENTO DE USO DE IMAGEM}

Não se aplica.

APROVAÇÃO DE COMITÊ DE ÉTICA EM PESQUISA

Não se aplica.

\section{CONFLITO DE INTERESSES}

Não se aplica.

\section{LICENÇA DE USO}

Este artigo está licenciado sob a Licença Creative Commons CC-BY. Com essa licença você pode compartilhar, adaptar, criar para qualquer fim, desde que atribua a autoria da obra.

\section{HISTÓRICO}

Recebido em: 01-02-2019

Aprovado em: 22-02-2019 